\title{
Development of a Decision Making Algorithm for Traffic Jams Reduction Applied to Intelligent Transportation Systems
}

\author{
David Gómez, ${ }^{1}$ José-Fernán Martínez, ${ }^{1,2}$ Juana Sendra, ${ }^{3}$ and Gregorio Rubio ${ }^{1,2}$ \\ ${ }^{1}$ Research Center on Software Technologies and Multimedia Systems for Sustainability (CITSEM), \\ Universidad Politécnica de Madrid (UPM), 28031 Madrid, Spain \\ ${ }^{2}$ Departamento de Ingeniería Telemática y Electrónica, Universidad Politécnica de Madrid (UPM), 28031 Madrid, Spain \\ ${ }^{3}$ Departamento de Matemática Aplicada a las TIC, Universidad Politécnica de Madrid (UPM), 28031 Madrid, Spain \\ Correspondence should be addressed to David Gómez; david.gomezs@upm.es
}

Received 27 May 2016; Revised 12 August 2016; Accepted 24 August 2016

Academic Editor: Giorgio Pennazza

Copyright (C) 2016 David Gómez et al. This is an open access article distributed under the Creative Commons Attribution License, which permits unrestricted use, distribution, and reproduction in any medium, provided the original work is properly cited.

\begin{abstract}
This paper is aimed at developing a decision making algorithm for traffic jams reduction that can be applied to Intelligent Transportation Systems. To do so, these algorithms must address two main challenges that arise in this context. On one hand, there are uncertainties in the data received from sensor networks produced by incomplete information or because the information loses some of the precision during information processing and display. On the other hand, there is the variability of the context in which these types of systems are operating. More specifically, Analytic Hierarchy Process (AHP) algorithm has been adapted to ITS, taking into account the mentioned challenges. After explaining the proposed decision making method, it is validated in a specific scenario: a smart traffic management system.
\end{abstract}

\section{Introduction}

Descriptively, Smart City [1-3] is an urban space with infrastructures, intelligent networks and platforms, with millions of sensors and actuators, constituting sensor networks [4], among which people and their mobile phones must also be included. It must provide the right information to the right users at the right time, in the right place, and on the right device.

One of the Smart Cities' main categories are Intelligent Transportation Systems (ITS) [5-7], which are a set of technical countermeasures for a wide range of transportation problems. For many years, the field has been developing and, at the present time, a large number of systems have been tested and deployed. ITS applications are mainly aimed to cope with congestion and road accidents, as well as to improve many other aspects of transportation, providing innovative services relating to different modes of transport and traffic management and enabling various users to be better informed and make safer, more coordinated, and smarter use of transport networks.
Decision making mechanisms are one of the essential parts of these systems. Based on the information collected from the context, the systems can be configured to change their behaviour whenever certain changes are detected. Using a proper decision making algorithm, traffic can be efficiently managed avoiding congestion and road accidents.

However, even when information collected from the context is highly detailed and accurate, complex and unexpected dynamics can emerge in such transportation systems. Uncertainty, sometimes called inaccuracy or noise, can arise in the information passing through these systems at the time of either collection, processing, or presentation. Information inaccuracy may occur either because the collected data produces incomplete information or because the information loses some of the precision during processing and display [8].

Therefore, it is important that decision making mechanisms consider information inaccuracy in order to make better decisions and avoid wrong decisions with all the undesirable and dangerous consequences; this can produce, for example, accidents, traffic jams, pollution increment, or energy waste [6]. A solution for decision making algorithms 
to deal with uncertainty has been the usage of fuzzy logic [9$11]$.

On the other hand, sensor networks are sensing information from a changeable context, so decision making algorithms should also take this into account in order to be able to adapt themselves to the current situation, optimizing decision making in order to choose the best solution at every moment.

In this paper, AHP decision making algorithm has been adapted to ITS for traffic jams reduction, considering both information inaccuracy and dynamic environment inherent to ITS. Section 2 presents a state of the art of some wellknown and widely applied decision making algorithms, showing the advantages and drawbacks of using them and reasoning why AHP has been chosen as the algorithm to be applied to ITS. In Section 3, AHP decision making algorithm is explained and discussed, and in Section 4 the proposed decision making algorithm is shown. In Section 5, the algorithm is applied to a specific scenario of ITS in order to test its suitability for reducing traffic jams in the mentioned framework. Finally, in Section 6 conclusions are presented.

\section{Related Work}

In decision making, distinction can be made between the cases whether having a single or multiple criteria. A decision problem may have a single criterion or a single aggregate measure like cost [12]. Then, the decision can be made implicitly by determining the alternative with the best value of the single criterion or aggregate measure. On the other hand, the case of having a finite number of criteria belongs to the field of Multiple Criteria Decision Making (MCDM). To address these cases, a large number of methods have been defined, mostly for MCDM, among which some of the main methods are weighting methods, Multi-Attribute Utility Theory (MAUT), outranking methods, fuzzy methods, Analytic Hierarchy Process (AHP), and Technique for Order of Preference by Similarity to Ideal Solution (TOPSIS). AHP algorithm will be shown and discussed in Section 3.

In this section, these methods will be briefly explained highlighting the main advantages and drawbacks that these algorithms present in order to consider whether they are suitable or not to be adapted and applied to the Intelligent Transportation Systems.

2.1. Weighting Methods. In these methods, weights are assigned the decision criteria and alternatives and then decision is made by applying addition or multiplication functions to the criteria and alternatives weights. These functions used for evaluating alternatives are based on the weighted sum or product. The best alternative is the one that yields the maximum total performance value. It is usually assumed that all the criteria are benefit criteria; that is, the higher the values are, the better they are. Several most known weighting methods are Weighted Sum Model (WSM) [13], Weighted Product Model (WPM) [13], Simple MultiAttribute Rating Technique (SMART) [14], SWING [15], and Trade-off Weighting [16].
These methods are applicable only when all the data are expressed in exactly the same unit. If this is not the case, then the final result has no sense. On the other hand, the weights for both alternatives and criteria must be previously defined in order to apply this algorithm and, therefore, it is not possible to adapt this algorithm to be applied to the Intelligent Transportation Systems since data received vary with time and they are not static.

\subsection{Multi-Attribute Utility Theory. Multi-Attribute Utility} Theory (MAUT) is a structured methodology designed to handle the trade-offs among multiple objectives. According to MAUT, the overall evaluation of an alternative is defined as a weighted addition of its evaluations with respect to its relevant value dimensions or criteria. These dimensions are evaluated with respect to their utility for the evaluator, using utility functions [17].

Utility functions can be applied to transform the raw performance values of the alternatives against diverse criteria, both factual (objective, quantitative) and judgmental (subjective, qualitative), to a common, dimensionless scale. They also convert the raw performance values so that a more preferred performance obtains a higher utility value. An example for this is a criterion reflecting the goal of cost minimization. The associated utility function must result in higher utility values for lower cost values [12].

All alternatives are evaluated using this function, and the one that maximizes the utility is selected. As in the weighting methods, to apply this group of methods, the weights of the alternatives and the criteria must be previously defined and, therefore, it is not possible to adapt this algorithm to be applied to the Intelligent Transportation Systems.

2.3. Outranking Methods. These methods [12] are based on a preference relation, usually called outranking relation, which indicates the degree of dominance of one alternative over another. This dominance is determined using two indices defining the concordance and discordance following the assumption that the first alternative is preferred to the second one. Thresholds are defined for both indices, so that if the concordance index is higher than defined threshold and the discordance one is lower, then the first alternative is preferred than the other. Dominated alternatives are eliminated, and, finally, a subset of the best alternatives is obtained. This procedure is applied until a suitable subset is obtained. Two well-known outranking methods are ELECTRE [18] and PROMETHEE [19].

These methods are suitable to select the best group of alternatives when there is a high number of them. However, since this method does not choose one alternative but a group of alternatives, it cannot be applied as an algorithm to make a unique and final decision, and therefore, another decision making algorithm which chooses one alternative must be selected to be used in the Intelligent Transportation Systems scenario.

2.4. Fuzzy Methods. These methods [9] employ the fuzzy sets theory to add flexibility and to enrich methods defining 
TABLE 1: AHP fundamental scale for pairwise comparisons.

\begin{tabular}{lcc}
\hline $\begin{array}{l}\text { Intensity of } \\
\text { importance }\end{array}$ & Definition & Explanation \\
\hline 1 & Equal importance & Two activities contribute equally to the objective \\
3 & Weak importance of one over another & Moderate importance or preference of one over another \\
5 & Strong importance & Strong importance or preference \\
7 & Demonstrated importance & Very strong importance \\
9 & Absolute importance & Extreme preference \\
$2,4,6,8$ & Intermediate values between the two adjacent judgements & When compromise is needed \\
\hline
\end{tabular}

the decision criteria and alternatives values like a set of fuzzy characteristics. Fuzzy sets are sets whose elements have degrees of membership. In contrast with classical set theory, in which the membership of elements in a set is assessed in binary terms, an element either belongs or does not belong to the set, and fuzzy set theory permits the gradual assessment of the membership of elements in a set. This is described with the aid of a membership function valued in the real unit interval $[0,1][20]$.

Fuzzy sets were introduced in decision making algorithms in order to deal with imprecision or vagueness of human thought and judgement as well as imprecision derived from making decisions in a real world scenario. Imprecision may arise from a variety of reasons: unquantifiable information, incomplete information, unobtainable information, and partial ignorance. Conventional multiple attribute decision making methods cannot effectively handle problems with such imprecise information [21].

The main advantage of fuzzy methods over nonfuzzy methods is that the former ones take into account uncertainty and interdependence between criteria and alternatives. Fuzzy methods provide more realistic, reliable, and logical results when applied to fuzzy environments than nonfuzzy methods, as demonstrated by some studies [21-23]. On the contrary, preferences determined by fuzzy methods can be inexact and shall be discussed.

2.5. TOPSIS. This method, proposed by [24-26], obtains a ranking of alternatives based on the closeness coefficient to the ideal solution. This coefficient considers the distance of the alternatives to the positive ideal solution and the negative ideal solution. The first solution maximizes the benefit criteria and minimizes the cost criteria, and the second solution maximizes the cost criteria and minimizes the benefit criteria. Therefore, the best alternative will be the one with the shortest distance to the positive ideal solution and the farthest distance to the negative ideal solution [27].

In order to make a decision this algorithm follows several steps. First, decision matrix is constructed and normalized. Then, the weighted normalized decision matrix is constructed. After this, positive ideal and negative ideal solutions are obtained. Next, for each alternative, its separation from positive ideal solution and from negative ideal solution is computed. Finally, relative closeness of each alternative to ideal solution is computed, and alternatives are ranked based on this coefficient.
This method has several advantages such that it is useful for qualitative and quantitative data, it is relatively easy and fast, with a systematic process, and it outputs a numerical value for each alternative that provides a better understanding of differences and similarities among alternatives [28]. On the other hand, it has some disadvantages such as correlations between criteria, uncertainty in obtaining the weights only by objective methods or subjective methods, and possibility of alternative closed to ideal point and nadir point concurrently [29].

\section{Analytic Hierarchy Process}

The Analytic Hierarchy Process (AHP) is one of the most widely applied MCDM algorithms. In this algorithm, the decision making problem is first decomposed into a hierarchy which consists of an overall goal, a group of options or alternatives for reaching the goal, and a group of factors or criteria that relate the alternatives to the goal. Once the hierarchy is built, the decision makers systematically evaluate its various elements by comparing them to one another, two at a time, alternatives or criteria, with respect to their impact on an element above them in the hierarchy, criteria or goal, respectively. To do so, a relative weight is assigned to every pairwise comparison of alternatives and criteria according to the scale shown on Table 1 [30].

These evaluations are converted into numerical values which represent the priorities for each element of the hierarchy. These priorities, also called weights, are obtained following basically two steps. First, local priorities of both criteria with respect to the goal, and alternatives with respect to each criterion are computed. To do so, the following equation is solved:

$$
\left[\begin{array}{cccc}
\frac{w_{1}}{w_{1}} & \frac{w_{1}}{w_{2}} & \cdots & \frac{w_{1}}{w_{n}} \\
\frac{w_{2}}{w_{1}} & \frac{w_{2}}{w_{2}} & \cdots & \frac{w_{2}}{w_{n}} \\
\vdots & \vdots & \cdots & \vdots \\
\frac{w_{n}}{w_{1}} & \frac{w_{n}}{w_{2}} & \cdots & \frac{w_{n}}{w_{n}}
\end{array}\right]\left[\begin{array}{c}
w_{1} \\
w_{2} \\
\vdots \\
w_{n}
\end{array}\right]=n\left[\begin{array}{c}
w_{1} \\
w_{2} \\
\vdots \\
w_{n}
\end{array}\right],
$$

where $w_{i} / w_{j}$ are the pairwise comparisons of each pair of alternatives or criteria compared, $w_{1} \cdots w_{n}$ are the local priorities, and $n$ is the main eigenvalue of the matrix of pairwise comparisons. 
Once local priorities for both criteria and alternatives have been obtained, total priorities are finally calculated for each of the decision alternatives. Total priority of an alternative is the sum of its local priorities with respect to each criterion, weighted by the weights of the corresponding criteria. Total priorities represent to what extent the alternatives are able to achieve the decision goal, so they allow a straightforward evaluation of the different possible actions.

Since criteria and alternative weights are not previously defined, this algorithm allows them to be adapted to a specific environment. Besides, decision is made following a simple procedure, easy to understand, apply, and implement, and it is able to choose one alternative. In addition, one of its main application fields are those related with transportation, such as route selection [31-34]. Therefore, this algorithm is suitable to be adapted and applied to the Intelligent Transportation Systems.

\section{Proposed AHP-Based Decision Making Method}

In this section, a decision making proposal that can be applied to Intelligent Transportation Systems is presented. More specifically, the main contributions of this paper are listed in Section 4.1. Then, the execution procedure of the proposed decision making algorithm will be presented and described in detail in Section 4.2.

4.1. Innovations. Although AHP algorithm has been extensively studied and widely applied and several variants of the algorithm have arisen, there is no variant of AHP considering, at the same time, uncertainties and variability in the input data applied to Intelligent Transportation Systems. This would enable the algorithm both to deal with inaccuracy of collected data due to incompleteness or precision losses of information during processing and display and to deal with dynamic changes in a real context. Such an algorithm would improve decisions made in smart traffic management systems, taking into account these two aspects that are present in these systems.

Therefore, in this paper, the AHP method has been adapted to Intelligent Transportation Systems by fusing two of its variants, Fuzzy AHP (FAHP) and Dynamic AHP (DAHP), for addressing two important aspects that arise in ITS: uncertainties in the data received from sensors [8] and the variability of the data received from the context.

On one hand, intervals instead of single values have been employed as relative weights of pairwise comparisons in order to model the inaccuracy that the data received from sensors can present, as previously mentioned. These intervals are triangular fuzzy numbers which are a class of fuzzy sets. This approach is the same as in Fuzzy AHP method [35] and, therefore, the above-mentioned weights are computed according to this method.

On the other hand, alternatives are considered as variables in function of time as in Dynamic AHP method [36]. Therefore, alternatives are checked periodically in order to detect possible changes in the context and readjust the relative weights of the pairwise comparisons if needed. Criteria are also readjusted periodically. One of the key aspects of this paper is that the Dynamic AHP method is implemented and validated with respect to a realistic scenario, by using MATLAB.

In addition, in the classic AHP algorithm, assignments of weights to the pairwise comparisons are made based on a subjective procedure, which uses the judgements of experts to evaluate the importance of each criterion considered over the others and, consequently, obtain their weights. However, in the proposed algorithm, assignments of fuzzy weights to the pairwise comparisons are made based on an objective procedure, which uses historical input traffic data obtained in order to compute both criteria and alternative weights. This enables the algorithm to operate both autonomously and adaptively without human intervention as well as avoid subjectiveness of human judgements.

This procedure consists in defining nine intervals for the pairwise differences of both criteria and alternatives, so that each interval has assigned one of the nine weights defined in FAHP algorithm. When the values of the pairwise comparisons fall into one of these intervals, the weight corresponding to that interval is assigned to these comparisons. In such a way, since the weights are assigned based on an objective procedure, errors produced by human judgements are avoided along with the negative impact these errors could involve such as greater traffic jams, higher amount of pollution, or waste of energy. In Sections 5.2 and 5.3, weights assignment procedure is explained in more detail.

In summary, decision making algorithm proposed in this paper presents three innovations:

(1) Fuzzy AHP and Dynamic AHP have been fused in order to deal with both inaccuracy and variability of input data in a real fuzzy and changeable context of a smart traffic management system, improving decisions made in order to be more realistic, reliable, and logical.

(2) An objective procedure has been added to the algorithm to compute both criteria and alternative weights based on historical input data traffic obtained instead of subjective human judgements. This enables an autonomous and adaptive process of quantitative input data.

(3) Implementation and simulation of the proposed decision making algorithm were done using MATLAB.

4.2. Execution Procedure. The execution of the proposed method will be performed following the steps shown in Figure 1.

In the following sections, this procedure will be described in detail.

4.2.1. Computing Weights of Criteria and Alternatives. Once the goal and criteria are determined, the criteria weights first, and then alternatives, are computed. This is done as in FAHP method, which embeds the fuzzy theory to AHP method to solve complex decision making problems in a 
TABLE 2: Triangular fuzzy numbers scale of the proposed algorithm.

\begin{tabular}{lccc}
\hline $\begin{array}{l}\text { Intensity of } \\
\text { importance }\end{array}$ & Definition & Fuzzy triangular scale & Reciprocal \\
\hline 1 & Equal importance & $(1,1,3)$ & $(1 / 3,1,1)$ \\
3 & Weak importance & $(1,3,5)$ & $(1 / 5,1 / 3,1)$ \\
5 & Strong importance & $(3,5,7)$ & $(1 / 7,1 / 5,1 / 3)$ \\
7 & Demonstrated importance & $(5,7,9)$ & $(1 / 9,1 / 7,1 / 5)$ \\
9 & Absolute importance & $(7,9,9)$ & $(1 / 9,1 / 9)$ \\
$2,4,6,8$ & Intermediate values & $(1,2,4),(2,4,6),(4,6,8),(6,8,9)$ & $(1 / 4,1 / 2,1),(1 / 6,1 / 4,1 / 2),(1 / 8,1 / 6,1 / 4),(1 / 9,1 / 8$, \\
& between the two adjacent & $1 / 6)$ \\
\hline
\end{tabular}

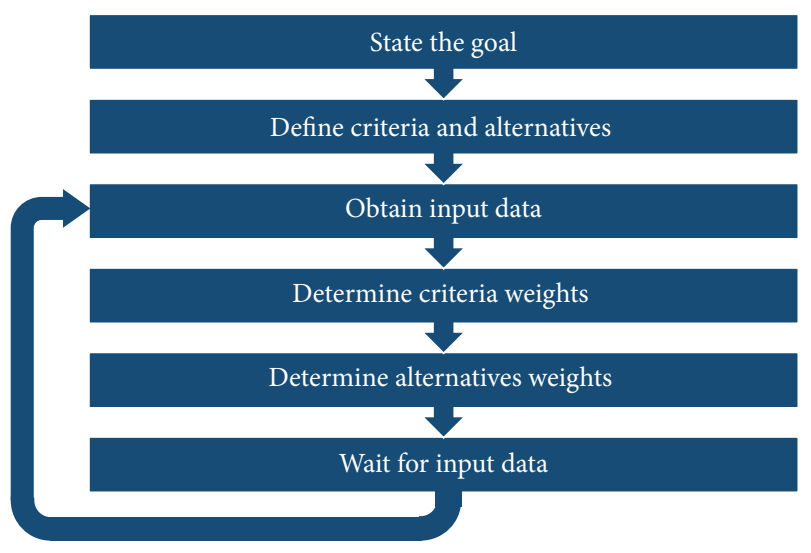

FIGURE 1: Proposed algorithm procedure.

fuzzy environment. The procedure to compute the weights is the following:

Step 1. Obtain input data, compare criteria/alternatives values in pairs, and assign a weight for each comparison using the intervals defined and a scale such as the one shown in Table 2. In this scale, triangular fuzzy numbers are used, which are fuzzy numbers represented with three points $(l, m, u)$, where $m$ is the modal value, $l$ stand for the lower bound, and $u$ stand for the upper bound [37]. This representation is interpreted as membership functions. It must be noted that the scale shown in Table 2 is only an example in which the lower and upper bounds of the intervals are at a distance of two units with respect to the center value but the range of the intervals can be chosen by the designer of the decision making method. The pairwise contribution matrix is shown in the following matrix:

$$
\widetilde{A}=\left(\begin{array}{cccc}
\widetilde{d}_{11} & \widetilde{d}_{12} & \cdots & \widetilde{d}_{1 n} \\
\widetilde{d}_{21} & \widetilde{d}_{22} & \cdots & \tilde{d}_{2 n} \\
\vdots & \vdots & \ddots & \vdots \\
\widetilde{d}_{n 1} & \widetilde{d}_{n 2} & \cdots & \tilde{d}_{n n}
\end{array}\right)
$$

where $\widetilde{d}_{i j}$ indicates the preference of $i$ th criterion over $j$ th criterion.
Step 2. The geometric mean of fuzzy comparison values of each criterion/alternative is calculated as shown in the following equation, where $\widetilde{r}_{i}$ still represents triangular values:

$$
\begin{aligned}
& \widetilde{r}_{i}=\left(\prod_{j=1}^{n} \widetilde{d}_{i j}[1], \prod_{j=1}^{n} \widetilde{d}_{i j}[2], \prod_{j=1}^{n} \widetilde{d}_{i j}[3]\right)^{1 / n}, \\
& i=1,2, \ldots, n,
\end{aligned}
$$

where $\widetilde{d}_{i j}[1]$ represents the lower bound, $\widetilde{d}_{i j}[2]$ the modal value, and $\widetilde{d}_{i j}$ [3] the upper bound of the fuzzy comparison values which form part of the pairwise contribution matrix.

Step 3. The fuzzy weights of each criterion can be obtained by following the next three substeps:

(a) Find the vector summation of each $\tilde{r}_{i}$.

(b) Find the (-1) power of summation vector. Replace the fuzzy triangular number, to make it in an increasing order.

(c) To find the fuzzy weight of criterion $i, \widetilde{w}_{i}$, each $\widetilde{r}_{i}$ must be multiplied with this reverse vector.

These substeps can be synthesized in the following equation:

$$
\widetilde{w}_{i}=\widetilde{r}_{i} \otimes\left(\widetilde{r}_{1} \oplus \widetilde{r}_{2} \oplus \cdots \oplus \widetilde{r}_{n}\right)^{-1}=\left(l w_{i}, m w_{i}, u w_{i}\right),
$$

where $\otimes$ represents the tensor product, $\oplus$ stands for the direct sum, $l w_{i}$ is the lower bound, $m w_{i}$ is the modal value, and $u w_{i}$ is the upper bound value of the fuzzy weight vector.

Step 4. Since computed weights $\widetilde{w}_{i}$ are still fuzzy triangular numbers, they need to be defuzzified by center of area method [38], by applying the next equation:

$$
M_{i}=\frac{l w_{i}+m w_{i}+u w_{i}}{3} .
$$

Step 5. Finally, we normalize $M_{i}$.

$$
N_{i}=\frac{M_{i}}{\sum_{i=1}^{n} M_{i}} .
$$


TABLE 3: Ranking values for each alternative and instant of time.

\begin{tabular}{lllll}
\hline & $T_{0}$ & $T_{1}$ & $\cdots$ & $T_{f}$ \\
\hline$A_{1}$ & $A_{10}$ & $A_{11}$ & $\cdots$ & $A_{1 f}$ \\
$A_{2}$ & $A_{20}$ & $A_{21}$ & $\cdots$ & $A_{2 f}$ \\
$A_{3}$ & $A_{30}$ & $A_{31}$ & $\cdots$ & $A_{3 f}$ \\
$A_{m}$ & $A_{m 0}$ & $A_{m 1}$ & $\cdots$ & $A_{m f}$ \\
\hline
\end{tabular}

\subsubsection{Adjusting Criteria and Alternatives Weights Periodically.} After determining the weights for the criteria, the alternatives are determined and their corresponding weights are computed with respect to criteria following the same steps as for the criteria. Then by multiplying each alternative weight with the corresponding criteria weights, the scores for each alternative are calculated in order to rank them and decide what is the best alternative. Then, after a certain period of time new input data is received and their weights are readjusted. Therefore, criteria and alternatives weights are not fixed values as considered in conventional AHP method but variables with time.

With this point of view, the proposed decision making method can be applied for each time new measures are received, but getting together all these pictures for each period, a dynamical representation of the system behaviour can be finally obtained where the system adjusts itself in an iterative process. Computing the weights in each period, the method determines the relative ranking of alternatives under each period as shown in Table 3. With the mentioned chart, it is possible to represent graphically the evolution of alternatives with time in order to obtain trends.

Therefore, the best decision under a dynamic context is not always what the AHP offers at a certain time, but that alternative which remains in prior positions in the ranking of alternatives during the period of time considered. The ranking obtained with the conventional AHP will refer to good decisions from a local point of view, but not necessarily under a temporary context. Therefore, the proposed method considers the time factor as a crucial aspect for taking decisions properly in a long term. By doing this, the system can be prepared to respond to a dynamic context in which changes occur with time.

\section{Application of the Proposed Algorithm to Intelligent Transportation Systems}

In this section, the decision making algorithm proposed in this paper will be applied to a specific scenario in order to demonstrate its suitability for being applied to the Intelligent Transportation Systems. The application scenario will be described in Section 5.1. The definition of intervals for criteria and alternatives weights assignment will be shown on Sections 5.2 and 5.3. Then, a numeric example of the proposed decision making algorithm will be developed in Section 5.4. Finally, the proposed algorithm will be compared to a variant of TOPSIS algorithm in order to evaluate its performance.
5.1. Scenario. The proposed decision making method will be applied to a smart traffic management system located in Madrid. The drivers can access the city through highways, but also there are ring roads that enable them to access the city at different points. In the proposed scenario, drivers are attempting to access Madrid using a highway, called A-3, and there are also two possible ring roads, named $\mathrm{M}-40$ and $\mathrm{M}$ 45 , in which drivers can be diverted.

Measurements are obtained from the traffic management system of the National Department of Traffic (DGT) [39], in Spain, which provides a large amount of real time traffic data that are integrated in Google Maps. The user can then easily collect traffic information from 4000 traffic sensors located over the Spanish road network. DGT traffic management system comprises different types of sensors such as electromagnetic loops, Road Weather Sensors, TV cameras, and fixed radars.

Electromagnetic loops measure traffic intensity, speed, flow, occupancy, distance between vehicles, and percentage of heavy vehicles, among other measurements. Road Weather Sensors measure atmospheric, precipitation, and road parameters such as air temperature, relative humidity, atmospheric pressure, global radiation, dew point, wind speed, direction and type, visibility, precipitation intensity, amount and type, height of the water layer and of the snow layer, state and temperature of the road surface, freezing temperature, and salinity. TV cameras monitor lots of sections of the main roads as well as accesses to cities and hot spots such as tunnels and bridges. Fixed radars monitor and control vehicles' speed.

Traffic historical data provided by DGT's sensors regarding traffic flow, number of vehicles/hour, average speed, in $\mathrm{km} / \mathrm{h}$, occupancy rate, which is the percentage of the measuring time that a car is occupying some place on the road, and percentage of light duty vehicles can be obtained from the DGT web page [40]. The user can also select the interval of time of his consultation, having the possibility of choosing between daily, weekly, or monthly historical data. Data generated by the sensors are periodically sent to the servers of the DGT.

A traffic control application obtains traffic data every minute, processes them, and decides the best road to access the city using the proposed decision making method. The best road is the one that has the lowest congestion level according to the data provided by the sensors. Therefore, the road with a higher traffic flow and average speed and a lower occupancy rate will be given preference over the others.

Finally, the application sends a message to a traffic panel, which is located on the highway before the diversions to the ring roads, indicating the best road for the drivers that attempt to access Madrid (see Figure 2).

Therefore, in the scenario explained above, the aim, the criteria, and the alternatives of the decision making method have been defined. The aim is to control the traffic in order to reduce the congestion on the roads. The criteria employed to evaluate the alternatives are the data obtained by the sensors deployed on the road, that is, traffic flow, average speed, and occupancy rate. The alternatives are the highway and the ring 


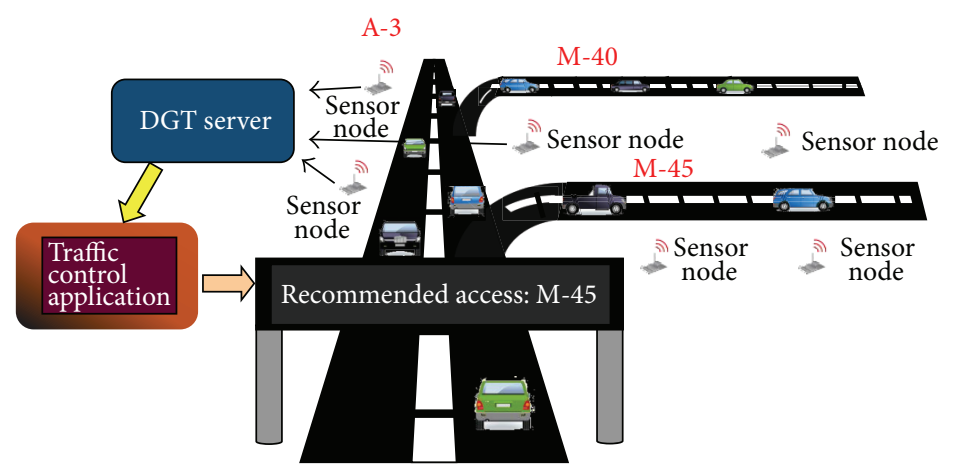

FIgURE 2: Application scenario.

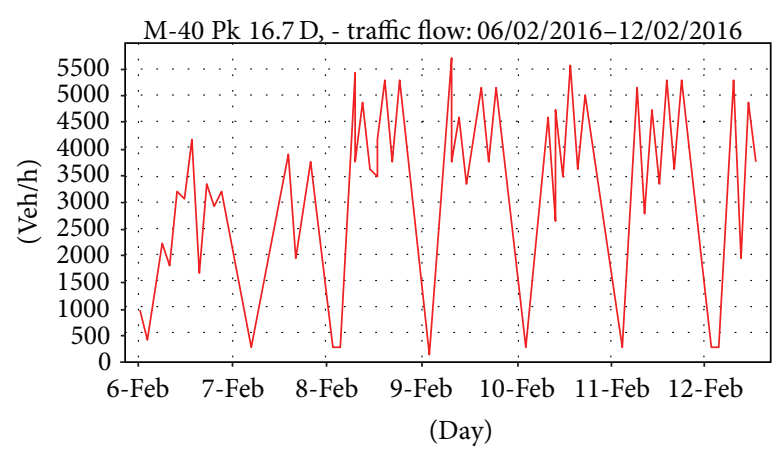

Figure 3: M-40 weekly historical data of traffic flow.

roads recommended to the drivers that are attempting to access Madrid: A-3, M-40, and M-45.

Once the aim, the criteria, and the alternatives have been defined, their respective weights should be calculated following the steps previously shown. Before computing the weights, the intervals that will be used for the pairwise comparison weights assignment should be defined for criteria and alternatives.

5.2. Definition of Intervals for Criteria Weights Assignment. In order to determine the weights of the criteria and evaluate the alternatives for the traffic management system, the values of the average speed, traffic flow, and occupancy rate periodically received by the traffic control application have been considered.

Concretely, the 50th percentile of the values received for each criterion, corresponding to the parameters measured in the A-3, M-40, and M-45, is computed. Then, it is divided into the weekly maximum value obtained from the historical data of DGT web page [40]. In this case, weekly historical data has been chosen since daily data could be not enough for obtaining a representative maximum historical value and, on the other hand, monthly data is a large amount of data to consider, and processing them could be computationally inefficient. On the other hand, the 50th percentile has been used for computing the criteria weights instead of other statistics such as the average, due to its robustness since it is not affected by outliers, and also it is the most resistant statistic, having a breakdown point of $50 \%$. Figures $3-5$ show

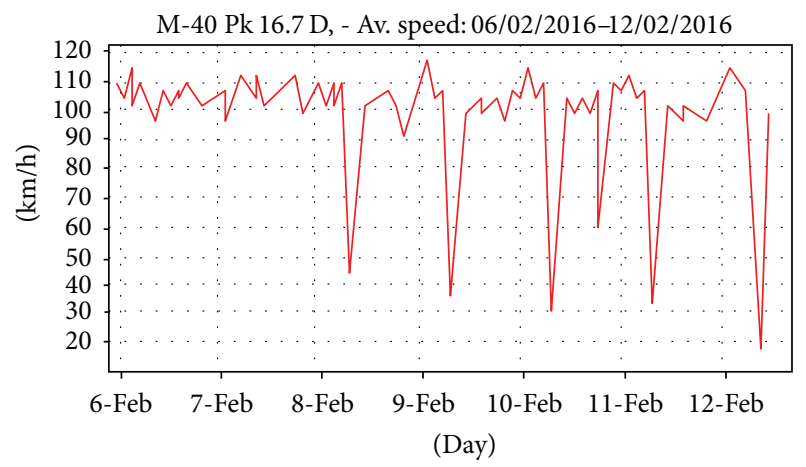

FIGURE 4: M-40 weekly historical data of average speed.

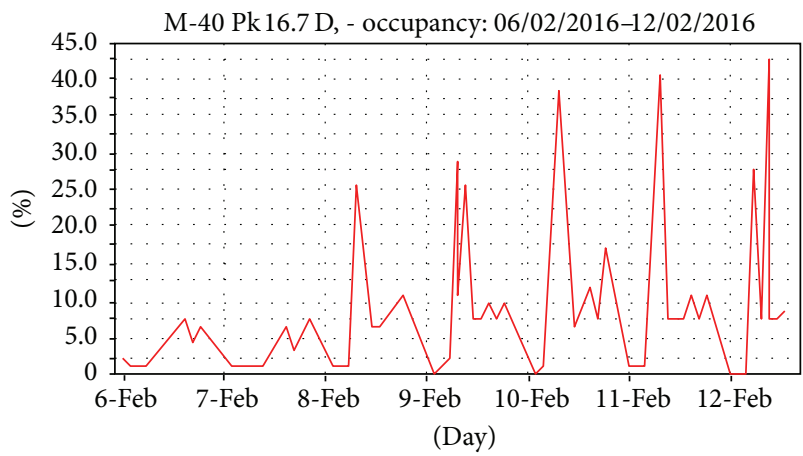

FIGURE 5: M-40 weekly historical data of occupancy rate.

the weekly historical data obtained from DGT web page for M-40.

Then, dividing the 50th percentile of the alternatives values for each criterion into the weekly maximum value, the percentage of the average with respect to its maximum value is computed for each criterion, giving an idea of how much is going to influence each criterion in the final decision. In the case of the occupancy rate, the complementary percentage is computed, because, in contrast with traffic flow and average speed, the lower occupancy is given preference instead of the higher.

After that, criteria are compared in pairs, computing at first the differences between the percentages previously obtained. Then, a fuzzy weight is assigned for each difference according to Table 4 . 
TABLE 4: Subintervals and fuzzy weights assigned for the percentages differences of the criteria.

\begin{tabular}{lc}
\hline Intervals & Fuzzy weights \\
\hline $0-0,1$ & $(1,1,3)$ \\
$0,1-0,2$ & $(1,2,4)$ \\
$0,2-0,3$ & $(1,3,5)$ \\
$0,3-0,4$ & $(2,4,6)$ \\
$0,4-0,5$ & $(3,5,7)$ \\
$0,5-0,6$ & $(4,6,8)$ \\
$0,6-0,7$ & $(5,7,9)$ \\
$0,7-0,8$ & $(6,8,9)$ \\
$0,8-0,9$ & $(7,9,9)$ \\
$0,9-1$ & $(7,9,9)$ \\
\hline
\end{tabular}

When the difference is negative, the reciprocal of the fuzzy weight of the corresponding interval will be assigned.

5.3. Definition of Intervals for Alternatives Weights Assignment. After obtaining the normalized nonfuzzy relative weights for criteria, the respective values for alternatives are found following the same methodology as described in Section 4.2.1. The alternatives should be pairwise compared with respect to each criterion particularly.

First of all, to obtain the weights of the pairwise comparisons the historical real data, obtained from the DGT web page as stated previously, has been used. For each measure and for each road, the maximum and the minimum values of the historical data have been extracted, and the interval between these two values has been divided into nine subintervals with the same length. By doing this, each one of the subintervals obtained can be associated with a single weight of the proposed method scale shown in Table 2.

For example, the maximum and minimum values of average speed measured from February 6 to February 12, 2016, were 125 and $15 \mathrm{~km} / \mathrm{h}$, respectively. The difference between these two values is $110 \mathrm{~km} / \mathrm{h}$ and dividing it into nine parts gives as a result nine subintervals with a length of $12,22 \mathrm{~km} / \mathrm{h}$. Then, a number of scales are assigned, in increasing order, so when the difference of measures at a certain time between two roads falls inside one of these intervals, the corresponding weight of the defined scale will be assigned to the corresponding pairwise comparison. Table 5 shows the subintervals for every measure and the fuzzy weights assigned to each one of them.

On the other hand, when the difference between the parameters compared is negative, the reciprocal of the fuzzy weight assigned to the corresponding subinterval in case it was positive will be employed as the relative weight of the pairwise comparison. For example, if the difference between traffic flows is $-100 \mathrm{veh} / \mathrm{h}$, if it were positive it would be assigned the fuzzy weight $(1,1,3)$ corresponding to the interval 0-638,9 veh/h. However, since the difference is negative, the reciprocal of this fuzzy weight is assigned to this pairwise comparison which is $(1 / 3,1,1)$. Fuzzy weights reciprocals are shown in Table 2.
TABLE 5: Subintervals and fuzzy weights assigned for the measurements considered as criteria.

\begin{tabular}{|c|c|c|}
\hline Criterion & Subintervals & Fuzzy weight \\
\hline \multirow{10}{*}{$\begin{array}{l}\text { Traffic flow (min: } \\
0 \text { veh/h, max: } \\
5750 \text { veh/h) }\end{array}$} & $0-638,9$ & $(1,1,3)$ \\
\hline & $638,9-1277,8$ & $(1,2,4)$ \\
\hline & $1277,8-1916,7$ & $(1,3,5)$ \\
\hline & $1916,7-2555,6$ & $(2,4,6)$ \\
\hline & $2555,6-3194,4$ & $(3,5,7)$ \\
\hline & $3194,4-3833,3$ & $(4,6,8)$ \\
\hline & $3833,3-4472,2$ & $(5,7,9)$ \\
\hline & $4472,2-5111,1$ & $(6,8,9)$ \\
\hline & $5111,1-5750$ & $(7,9,9)$ \\
\hline & $>5750$ & $(7,9,9)$ \\
\hline \multirow{10}{*}{$\begin{array}{l}\text { Average speed } \\
\text { (min: } 15 \mathrm{~km} / \mathrm{h} \text {, } \\
\max : 125 \mathrm{~km} / \mathrm{h})\end{array}$} & $0-12,22$ & $(1,1,3)$ \\
\hline & $12,22-24,44$ & $(1,2,4)$ \\
\hline & $24,44-36,67$ & $(1,3,5)$ \\
\hline & $36,67-48,89$ & $(2,4,6)$ \\
\hline & $48,89-61,11$ & $(3,5,7)$ \\
\hline & $61,11-73,33$ & $(4,6,8)$ \\
\hline & $73,33-85,56$ & $(5,7,9)$ \\
\hline & $85,56-97,78$ & $(6,8,9)$ \\
\hline & $97,78-110$ & $(7,9,9)$ \\
\hline & $>110$ & $(7,9,9)$ \\
\hline \multirow{10}{*}{$\begin{array}{l}\text { Occupancy rate } \\
\text { (min: } 0 \% \text {, max: } \\
43 \% \text { ) }\end{array}$} & $0-4,78$ & $(1 / 3,1,1)$ \\
\hline & $4,78-9,56$ & $(1 / 4,1 / 2,1)$ \\
\hline & $9,56-14,33$ & $(1 / 5,1 / 3,1)$ \\
\hline & $14,33-19,11$ & $(1 / 6,1 / 4,1 / 2)$ \\
\hline & $19,11-23,89$ & $(1 / 7,1 / 5,1 / 3)$ \\
\hline & $23,89-28,67$ & $(1 / 8,1 / 6,1 / 4)$ \\
\hline & $28,67-33,44$ & $(1 / 9,1 / 7,1 / 5)$ \\
\hline & $33,44-38,22$ & $(1 / 9,1 / 8,1 / 6)$ \\
\hline & $38,22-43$ & $(1 / 9,1 / 9,1 / 7)$ \\
\hline & $>43$ & $(1 / 9,1 / 9,1 / 7)$ \\
\hline
\end{tabular}

5.4. Example. After clarifying the procedure for determining weights of criteria and alternatives, an example will be presented in order to illustrate the operation of the proposed decision making method. First of all, input data are received at a certain instant of time. Table 6 shows the values of the criteria measured at 6:00 am on February 12, 2016.

Next, the 50th percentile of the alternatives values received as input data is obtained for each criterion. Then, each 50th percentile value is divided into the maximum historical value received of the corresponding criterion in order to obtain the percentage with respect to that maximum as can be seen in Table 7 .

After that, criteria are compared in pairs, and the weight for each comparison is obtained from the differences between their corresponding percentages previously computed, using the intervals defined in Table 4. Matrices of pairwise differences and fuzzy weights obtained are shown in Tables 8 and 9. It must be noted that, in the case of the occupancy rate, 
TABLE 6: Input data for the example.

\begin{tabular}{lccccc}
\hline Criteria $\backslash$ alternatives & A-3 & M-40 & M-45 & \multicolumn{2}{c}{ Criteria ordered } \\
& & 750 & 2400 & 250 & 250 \\
\hline Traffic flow $(\mathrm{veh} / \mathrm{h})$ & 98 & 103 & 112 & 2400 \\
Average speed $(\mathrm{km} / \mathrm{h})$ & 1 & 5 & 0 & 98 & 103 \\
Occupancy rate $(\%)$ & 112 & 0 & 1 \\
\hline
\end{tabular}

TABLE 7: Average and percentage with respect to maximum for each criterion.

\begin{tabular}{lcc}
\hline Criteria & $\begin{array}{c}\text { 50th } \\
\text { percentile }\end{array}$ & $\begin{array}{c}\text { Percentage with respect } \\
\text { to maximum }\end{array}$ \\
\hline Traffic flow $(\mathrm{veh} / \mathrm{h})$ & 750 & $750 / 5750=0,130$ \\
Average speed $(\mathrm{km} / \mathrm{h})$ & 103 & $103 / 125=0,824$ \\
Occupancy rate $(\%)$ & 1 & $1-(1 / 43)=0,977$ \\
\hline
\end{tabular}

TABLE 8: Matrix of pairwise differences for criteria.

\begin{tabular}{lccc}
\hline Criteria & $\begin{array}{c}\text { Traffic } \\
\text { flow }\end{array}$ & $\begin{array}{c}\text { Average } \\
\text { speed }\end{array}$ & $\begin{array}{c}\text { Occupancy } \\
\text { rate }\end{array}$ \\
\hline $\begin{array}{l}\text { Traffic flow (veh/h) } \\
\text { Average speed } \\
\text { (km/h) }\end{array}$ & 0 & $-0,694$ & $-0,847$ \\
$\begin{array}{l}\text { Occupancy rate } \\
(\%)\end{array}$ & 0,694 & 0 & $-0,153$ \\
\hline
\end{tabular}

TABLE 9: Matrix of pairwise comparisons fuzzy weights for criteria.

\begin{tabular}{lccc}
\hline Criteria & $\begin{array}{c}\text { Traffic } \\
\text { flow }\end{array}$ & $\begin{array}{c}\text { Average } \\
\text { speed }\end{array}$ & $\begin{array}{c}\text { Occupancy } \\
\text { rate }\end{array}$ \\
\hline Traffic flow & $(1,1,3)$ & $(1 / 9,1 / 7$, & $(1 / 9,1 / 9$, \\
Average speed & $(5,7,9)$ & $(1,1,3)$ & $1 / 7)$ \\
Occupancy rate & $(7,9,9)$ & $(1,2,4)$ & $(1,1,1 / 2,1)$ \\
\hline
\end{tabular}

the complementary percentage has been computed because, as explained before, in contrast with traffic flow and average speed, the lower occupancy is given preference instead of the higher.

After obtaining the pairwise comparison matrix of fuzzy weights, the next step is to calculate the geometric mean of fuzzy comparison values of each criterion, using (3), as follows:

$$
\begin{aligned}
\tilde{r}_{i} & =\left[\left(1 \cdot \frac{1}{9} \cdot \frac{1}{9}\right)^{1 / 3} ;\left(1 \cdot \frac{1}{7} \cdot \frac{1}{9}\right)^{1 / 3} ;\left(3 \cdot \frac{1}{5} \cdot \frac{1}{7}\right)^{1 / 3}\right] \\
& =[0,231 ; 0,251 ; 0,441] .
\end{aligned}
$$

Hence, the geometric means of fuzzy comparison values of criteria are shown in Table 10.

After this, the relative fuzzy weights of criteria are obtained by using (4), that is, multiplying the geometric mean of each criterion by the inverse of the vector summation in increasing order, which is the last row of the previous table,
TABLE 10: Geometric means $\left(\widetilde{r}_{i}\right)$ of criteria.

\begin{tabular}{lccc}
\hline Criteria & \multicolumn{3}{c}{$\tilde{r}_{i}$} \\
\hline Traffic flow & 0,231 & 0,251 & 0,441 \\
Average speed & 1,077 & 1,518 & 3 \\
Occupancy rate & 1,913 & 2,621 & 4,762 \\
Total & 3,211 & 4,39 & 8,203 \\
Reverse (power of -1$)$ & 0,311 & 0,228 & 0,122 \\
Increasing order & 0,122 & 0,228 & 0,311 \\
\hline
\end{tabular}

as shown as an example in the next equation for the traffic flow:

$$
\begin{aligned}
\widetilde{w}_{i} & =[(0,231 \cdot 0,122) ;(0,251 \cdot 0,228) ;(0,441 \cdot 0,311)] \\
& =[0,028 ; 0,057 ; 0,137]
\end{aligned}
$$

Table 11 shows the relative fuzzy weights of criteria.

Finally, the average of the fuzzy weights are computed for each criterion, $M_{i}$, and after that, this average is normalized obtaining nonfuzzy relative weights, $N_{i}$. Table 12 shows the results for this example.

Once the normalized nonfuzzy relative weights of the criteria have been obtained, the same methodology is applied to find the weights for alternatives. But now, the different alternatives are compared in pairs for each criterion, obtaining the weight for each comparison, using Table 5. However, since it would be burdensome to explain the same procedure for every criterion, only the normalized nonfuzzy relative weights of each alternative with respect to each criterion as well as their total scores are tabulated in Table 13.

Depending on this result, alternative M- 45 has the highest total score. Therefore, it is suggested as the best road at the instant of time considered, in terms of congestion, according to the selected criteria.

Following the same procedure, the traffic control application obtains the best road recalculating the weights of the pairwise comparisons every time the application receives new input data of the considered roads from the DGT web page. By doing this, a graphical representation of the alternatives weights computed at every period of time can be plotted.

This enables us to make an analysis of the alternatives' evolution with time and see what is the best road for driving not only at a certain instant of time but also in a whole period of time. This also enables the study of data trends, prediction of the system behaviour, and the best road in advance.

In order to evaluate the effectiveness of the proposed algorithm, total scores for the alternatives have been computed at eleven instants of time, from 6:00 am to 11:00 am, 
TABLE 11: Fuzzy weights $\left(\widetilde{w}_{i}\right)$ of criteria.

\begin{tabular}{lccc}
\hline Criteria & & $\widetilde{w}_{i}$ & \\
\hline Traffic flow & 0,028 & 0,057 & 0,137 \\
Average speed & 0,131 & 0,346 & 0,931 \\
Occupancy rate & 0,233 & 0,597 & 1,478 \\
\hline
\end{tabular}

TABLE 12: Averaged and normalized relative weights of each criterion.

\begin{tabular}{lcc}
\hline Criteria & $M_{i}$ & $N_{i}$ \\
\hline Traffic flow & 0,074 & 0,056 \\
Average speed & 0,469 & 0,358 \\
Occupancy rate & 0,769 & 0,586 \\
\hline
\end{tabular}

TABLE 13: Aggregated results for each alternative according to each criterion.

\begin{tabular}{lcccc}
\hline \multirow{2}{*}{ Criteria } & Weights & \multicolumn{3}{c}{$\begin{array}{c}\text { Scores of alternatives with } \\
\text { respect to related criterion }\end{array}$} \\
& & A-3 & M-40 & M-45 \\
\hline Traffic flow & 0,056 & 0.253 & 0.592 & 0.155 \\
Av. speed & 0,358 & 0.222 & 0.311 & 0.467 \\
Occupancy rate & 0,586 & 0.311 & 0.222 & 0.467 \\
\hline & Total & 0,276 & 0,275 & 0,449 \\
\hline
\end{tabular}

with a period of half an hour. At the first time instant, traffic state has been simulated as it is at the beginning of the input data obtained from DGT web page, as shown in the previous example. Then, for each instant of time, it has been considered that the $10 \%, 30 \%$, and $50 \%$ of the drivers follow the recommendations of the smart traffic management system, considering the input data used at the previous time instant modified according to the percentage of compliant drivers. By doing so, a realistic example is given, considering input data that varies dynamically according to drivers' choices, and the impact of the proposed decision making algorithm in managing and reducing traffic jams can be properly tested. Table 14 shows the highest ranked alternative at each instant of time for the different percentages of compliant drivers, and Figure 6 shows the evolution of alternative weights with time considering the above-mentioned percentages of compliant drivers.

5.5. Comparative Analysis of AHP-Based Proposed Algorithm and Fuzzy TOPSIS Method. In order to test the solidity of the proposed algorithm, it has been compared with another wellknown MCDM algorithm, TOPSIS, which has received much interest among researchers and practitioners and it is used across different application areas including transportation [27].

First, Fuzzy TOPSIS algorithm has been applied to the application case shown in the previous section in order to see its behaviour compared with the proposed algorithm. Then, both algorithms have been compared according to the factors considered in [41] that are relevant for the application case of the proposed algorithm.
5.5.1. Fuzzy TOPSIS Application. When applying Fuzzy TOPSIS algorithm to the application case shown in the previous section, output shown in Figure 7 was obtained. Table 15 shows the highest ranked alternative for each instant of time and for the different percentages of drivers which follow the recommendations of the smart traffic management system.

As can be seen, the highest ranked alternatives in most of the considered time instants are both M-40 and A-3, whereas in the proposed algorithm the highest ranked alternatives are M-40 and M-45 (see Figure 6). Although both algorithms behave similarly alternating the best suggested roads equally, there are two main differences that can be noticed between them.

First, alternatives weights are closer at each time instant in the proposed algorithm than in Fuzzy TOPSIS. This shows that the proposed algorithm manages better the traffic situation, distributing it equally between the possible roads and not allowing a high level of traffic load in any of them.

On the other hand, the second difference is that, in the proposed algorithm, distances between alternative weights, for each time instant, increase as the number of compliant drivers increases too, whereas these distances barely vary with the number of compliant drivers in Fuzzy TOPSIS. This shows that the proposed algorithm is more sensitive to traffic load changes than Fuzzy TOPSIS and, therefore, it presents a higher level of adaptability to manage changes in the traffic state.

5.5.2. Adequacy to Changes of Alternatives. When routing the traffic, changes in the road map can be made as a consequence of the building of new roads, so the inclusion of new alternatives should be considered. However, one of the main effects that can arise in some decision making algorithms, such as AHP and Fuzzy TOPSIS, when including new alternatives is the rank reversal [42]. This happens when the worst ranked alternative before including new alternatives in the algorithm becomes the best one after including them. This effect has been considered by some studies as a flaw in the AHP method [42-44].

Therefore, in order to test the consistency of the preference order of alternatives obtained by the compared algorithms, an additional alternative, called $A_{4}$, has been added with respect to the example previously shown. Three tests were performed for each decision making algorithm, each one with the additional alternative having a rating equal to one of the three existing alternatives. In addition, equal weights for all the criteria were applied. For the sake of clarity and simplicity, in these tests only the case of having a $10 \%$ of compliant drivers has been considered.

Before adding the new alternative, the highest ranked alternatives were equally M- 40 and M- 45 whereas A- 3 was the worst ranked in the AHP-based proposed algorithm application case. On the other hand, in the Fuzzy TOPSIS application case, A-3 and M-40 were the highest ranked alternatives while $\mathrm{M}-45$ was the lowest ranked.

After adding the new alternative to both algorithms, there were no significant changes in the ranking of alternatives except when the new alternative has a rating equal to M- 40 . Figures 8 and 9 show the evolution of the alternatives weights 

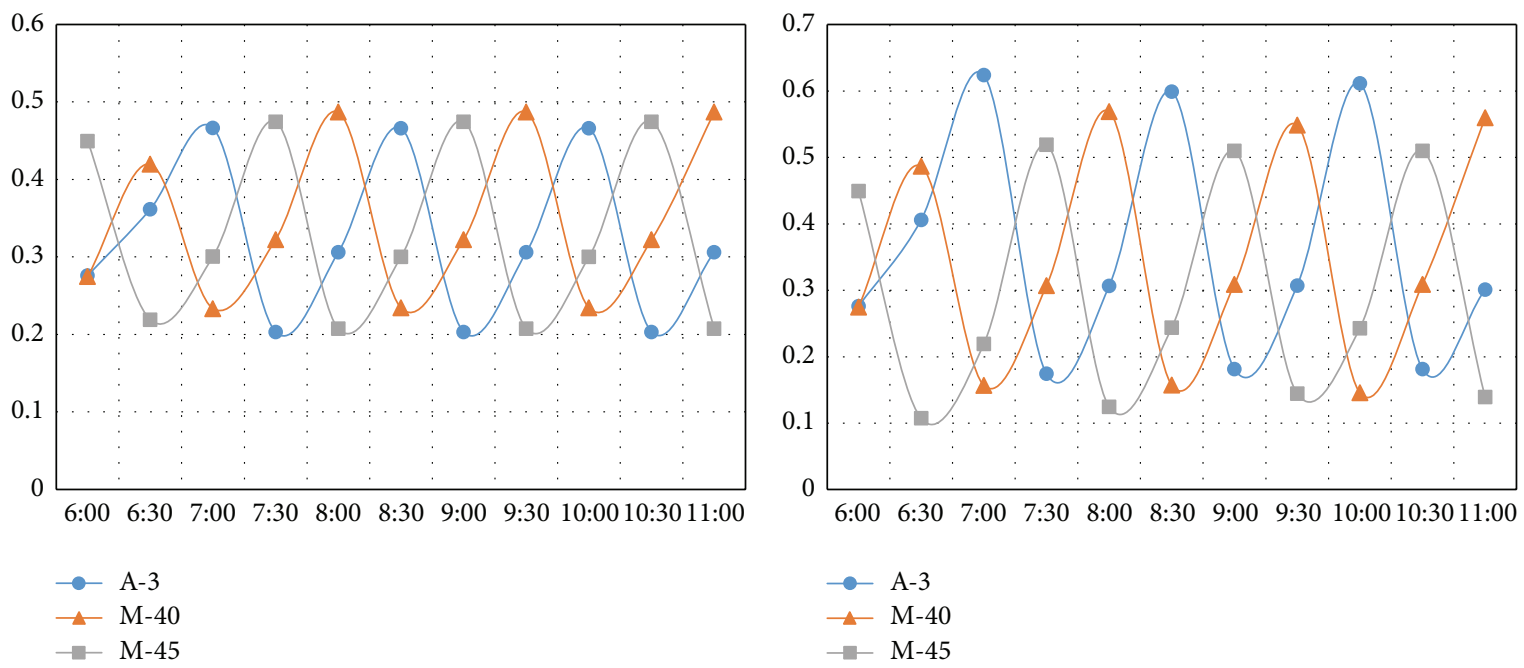

(a)

(b)

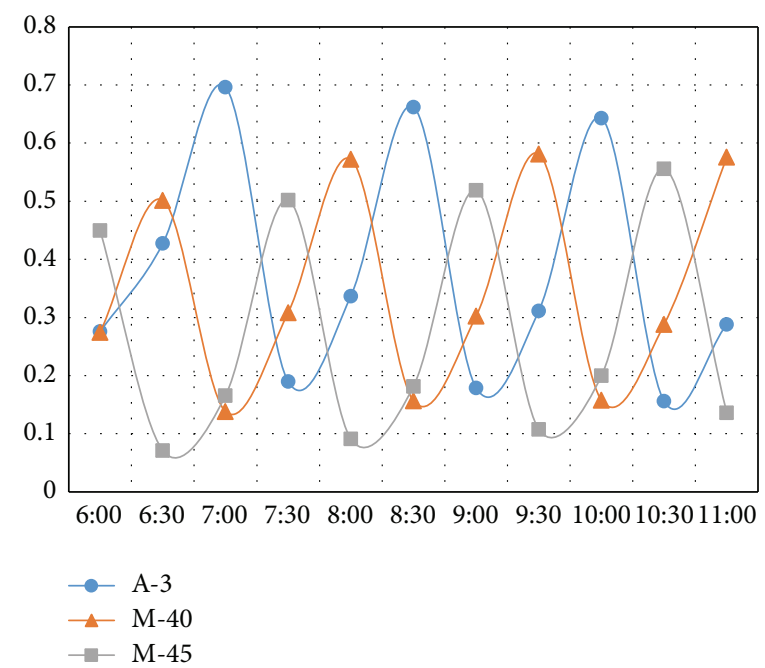

(c)

FIGURE 6: Evolution of alternative weights with time for the proposed algorithm when the percentages of compliant drivers are $10 \%$ (a), $30 \%$ (b), and 50\% (c).

TABLE 14: Highest ranked alternative at each instant of time for the proposed algorithm considering different percentages of compliant drivers.

\begin{tabular}{lccccccccccc}
\hline $\begin{array}{l}\text { Percentage of } \\
\text { compliant drivers }\end{array}$ & 6:00 & 6:30 & $7: 00$ & $7: 30$ & $8: 00$ & $8: 30$ & $9: 00$ & $9: 30$ & $10: 00$ & $10: 30$ & $11: 00$ \\
\hline $10 \%$ & M-45 & M-40 & A-3 & M-45 & M-40 & A-3 & M-45 & M-40 & A-3 & M-45 & M-40 \\
$30 \%$ & M-45 & M-40 & A-3 & M-45 & M-40 & A-3 & M-45 & M-40 & A-3 & M-45 & M-40 \\
$50 \%$ & M-45 & M-40 & A-3 & M-45 & M-40 & A-3 & M-45 & M-40 & A-3 & M-45 & M-40 \\
\hline
\end{tabular}

TABLE 15: Highest ranked alternative at each instant of time for Fuzzy TOPSIS algorithm considering different percentages of compliant drivers.

\begin{tabular}{lcccccccccrr}
\hline $\begin{array}{l}\text { Percentage of } \\
\text { compliant drivers }\end{array}$ & 6:00 & 6:30 & $7: 00$ & $7: 30$ & $8: 00$ & $8: 30$ & $9: 00$ & $9: 30$ & $10: 00$ & $10: 30$ & $11: 00$ \\
\hline $10 \%$ & A-3 & M-40 & M-45 & A-3 & M-40 & M-45 & A-3 & M-40 & M-45 & A-3 & M-40 \\
$30 \%$ & A-3 & M-40 & M-45 & A-3 & M-40 & M-45 & A-3 & M-40 & M-45 & A-3 & M-40 \\
$50 \%$ & A-3 & M-40 & M-45 & A-3 & M-40 & M-45 & A-3 & M-40 & M-45 & A-3 & M-40 \\
\hline
\end{tabular}




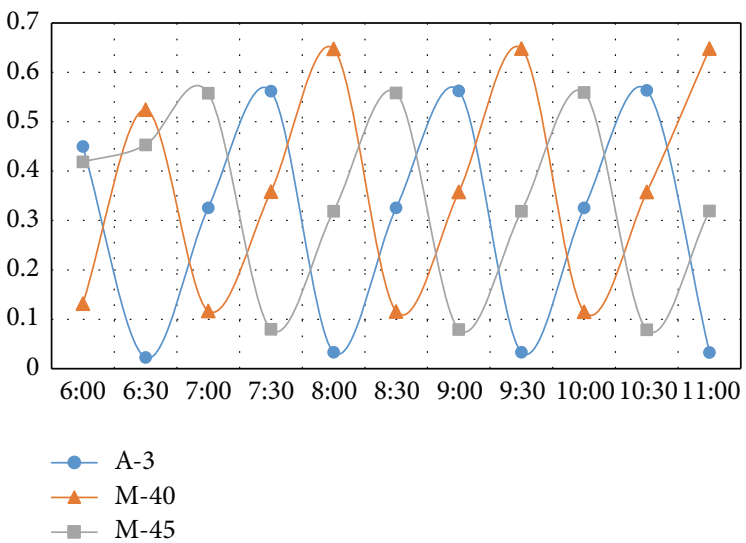

(a)

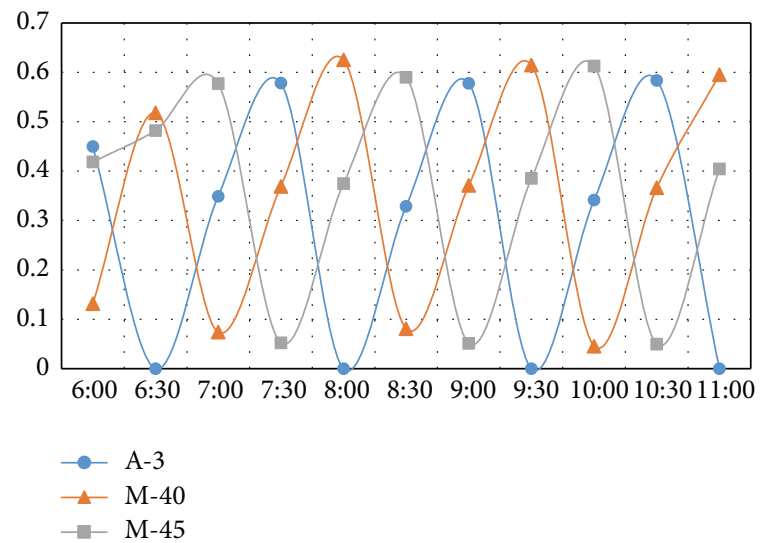

(b)

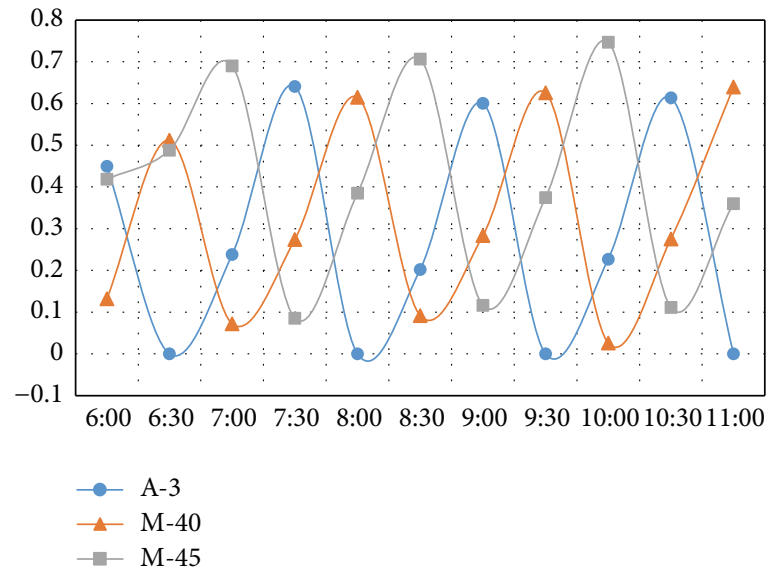

(c)

FIGURE 7: Evolution of alternative weights with time for Fuzzy TOPSIS algorithm when the percentages of compliant drivers are 10\% (a), 30\% (b), and $50 \%(c)$.

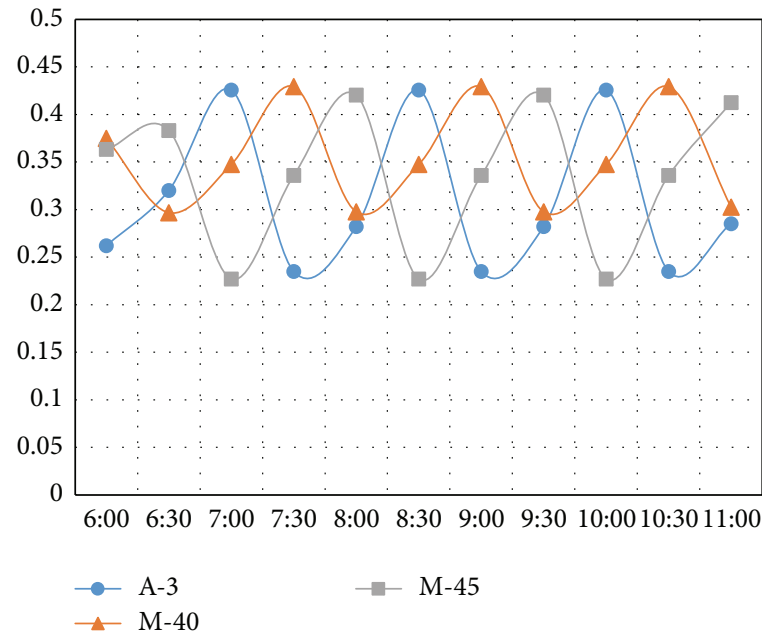

(a)

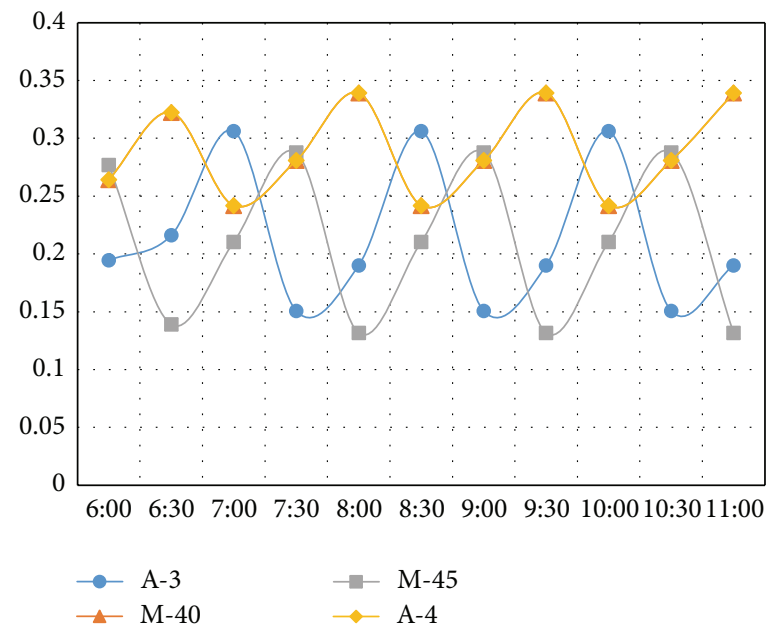

(b)

FIGURE 8: Importance order of alternatives for each instant of time in the proposed algorithm before adding a new alternative (a) and after adding it with a rating equal to M-40 (b). 


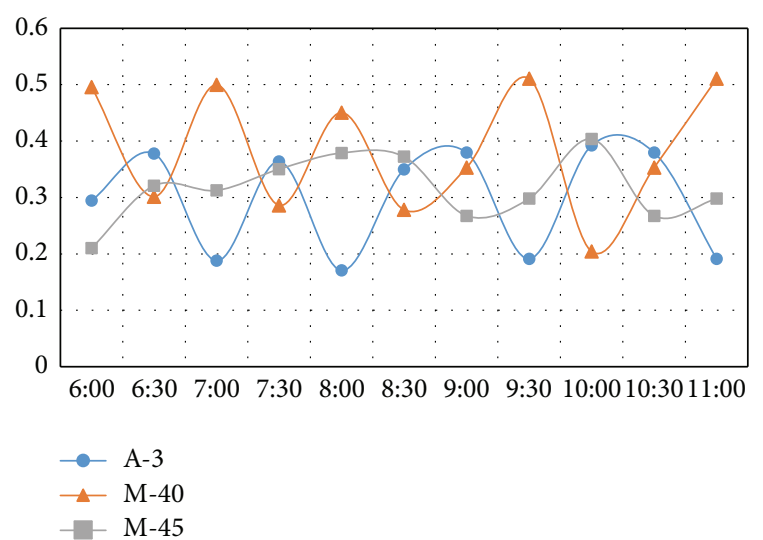

(a)

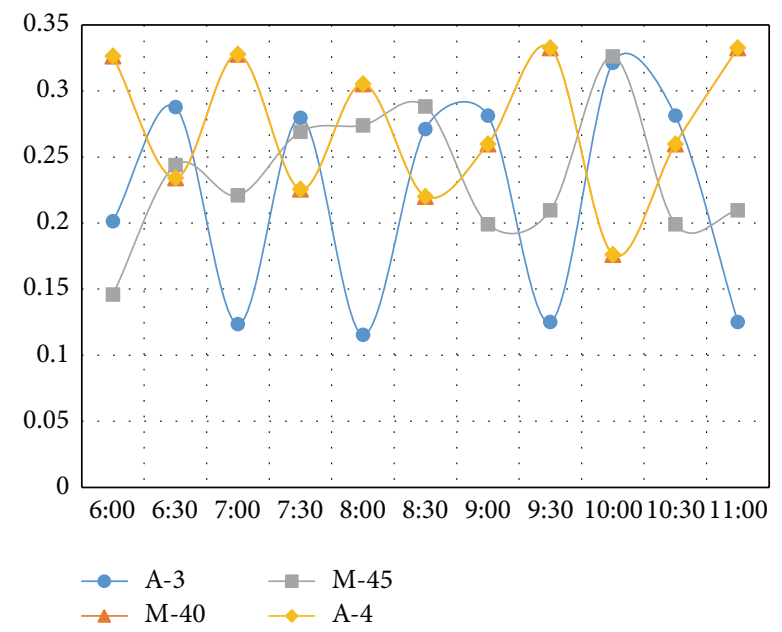

(b)

FIGURE 9: Importance order of alternatives for each instant of time in the Fuzzy TOPSIS algorithm before adding a new alternative (a) and after adding it with a rating equal to M-40 (b).

within the interval of time considered, before and after adding the new alternative, when applying the proposed algorithm and Fuzzy TOPSIS.

As can be appreciated in the previously mentioned figures, in the proposed algorithm application case, rank reversal happens at 6:30 whereas, in the Fuzzy TOPSIS application case, there is no rank reversal. So, although both algorithms present high consistency against rank reversal, according to the results obtained, it can be stated that Fuzzy TOPSIS algorithm provides a more consistent importance order of alternatives than the proposed algorithm for the considered application case.

However, depending on the application case, rank reversal must not necessarily be taken into account as a flaw in the decision making algorithm, but as a logical consequence of the addition of a new alternative to evaluate. For example, in the case of traffic routing, the building of new roads could change the traffic situation to such an extent that the worst road in terms of congestion before building the new road could become the best road after building it, at least in some instants of time. Therefore, rank reversal is not such a critical factor so as to choose Fuzzy TOPSIS instead of the proposed algorithm in the presented scenario.

In addition, the proposed algorithm outputs more logical results than Fuzzy TOPSIS since, before adding the new alternative, the latter does not rank M-45 as one of the best roads in the considered period of time, whereas according to the input data it is the best road in most of the time instants.

5.5.3. Adequacy to Changes of Criteria. In traffic routing situations, it could be useful to add new criteria to the decision making algorithm in order to improve the evaluation of the alternatives and, consequently, the traffic routing and to reduce traffic jams. Besides, rank reversal can arise when adding new criteria as shown in [41], so, in this case, consistency of the proposed algorithm can also be tested.

Therefore, as in the previous case, three tests for each algorithm have been performed, adding an additional criterion, called $C_{4}$, with a rating equal to one of the three existing criteria.

Before adding the new criterion, the importance order of criteria was OccupancyRate > AverageSpeed > TrafficFlow in both algorithms for the proposed application case. After adding the new criterion, there were no changes in the criteria importance order for both algorithms. Therefore, since no rank reversal happened, it can be concluded that both algorithms provide a consistent importance order for the criteria.

5.5.4. Computational Complexity. This factor refers to the number of operations required for the decision making algorithm to compute the final scores of the considered alternatives. According to [41], and taking into account that no degrees of possibility are computed in the proposed algorithm, the computational complexity, $T_{n, m}$, of the Fuzzy AHP method is given by the following equation:

$$
T_{n, m}=6 m(n+1)+n(m+1)+n m,
$$

where $n$ are the number of alternative roads and $m$ the number of criteria. On the other hand, computational complexity of the Fuzzy TOPSIS method is $20 \mathrm{~nm}$.

Since in the proposed application example $m=3$ and $n=$ 3 , the number of operations needed is 93 for the AHP-based proposed algorithm and 180 for the Fuzzy TOPSIS algorithm. Therefore, the proposed algorithm is more efficient than Fuzzy TOPSIS algorithm in this application example.

\section{Conclusions}

This work has been aimed at developing a decision making algorithm for traffic jams reduction that can be applied to ITS. For that purpose, a traditional and widely used decision making algorithm, named AHP, has been adapted to this context by fusing two of its variants: FAHP and DAHP.

The proposed decision making algorithm benefits from FAHP method in the use of fuzzy intervals as pairwise weights, instead of single values, in order to model the uncertainties that can arise in the information passing through transportation management systems at the time of either collection from sensors, processing, or presentation, 
because the collected data produces incomplete information or because the information loses some of the precision during processing and display.

On the other hand, the benefit from DAHP algorithm is the possibility of refreshing and recalculating the weights of the alternatives every time the new input data are received. That enables the proposed method to be adapted to the changes of the environment and respond properly to them. It also has the advantage of enabling an analysis and representation of the historical information of the different alternatives weights in order to see their trends and predict the behaviour of the system.

In turn, this analysis and trend computation could be used to predict congestions on the roads in order to make decisions in advance, which would lead to avoiding traffic jams in advance, saving fuel and energy, and improving mobility. This also leads to fostering commerce and domestic markets and contributes to the countries development boosting not only economy but also environmental care and, therefore, enabling a sustainable development.

In order to see the operation and suitability of the proposed decision making method for ITS, it has been applied to a smart traffic management system, located on a certain segment of the highway called A-3 in Madrid, between kilometric points 6 and 12. Basically, a traffic control application receives periodically input values of traffic flow, average speed, and occupancy rate, retrieved from DGT web page, and, executing the proposed decision making algorithm, obtains the best road among the ones comprised in the road segment, in this case A-3, M-40, and M-45.

More specifically, input values in eleven instants of time with a half an hour of difference, from 6 am to $11 \mathrm{am}$ of February 12, 2016, have been taken in order to test the operation of the decision making algorithm. It has been considered that the $10 \%, 30 \%$, and $50 \%$ of the drivers follow the recommendations of the smart traffic management system in order to give a realistic example, using dynamic input data, and see the impact of the proposed decision making algorithm in reducing traffic jams.

Results show that the best roads during the considered period of time are M-40 and M- 45 ring roads. On the other hand, the worst road for driving, during the time considered, is A-3 highway. The results obtained make sense, because A-3 is one the main roads in Spain, and it tends to be very busy in rush hour periods, such as the time period considered in the example.

Finally, for testing the validity and effectiveness of the proposed algorithm, it has been compared with a variant of a well-known decision making algorithm called TOPSIS. The comparison has been performed based on four factors: application of Fuzzy TOPSIS to the proposed example, adequacy to changes of alternatives, adequacy to changes of criteria, and computational complexity.

After applying Fuzzy TOPSIS algorithm to the proposed example, and comparing it with the proposed decision making algorithm, it is concluded that the latter one has two main advantages over the former one. On one hand, the proposed algorithm distributes more equally the traffic between the considered roads, avoiding a high level of traffic load in any of them. On the other hand, because the proposed algorithm is more sensitive to traffic load changes, which makes it present a higher level of adaptability to changes in the traffic state.

Regarding the adequacy of changes of both alternatives and criteria, a new alternative and criterion have been added, respectively, to test the consistency of both algorithms with respect to rank reversal. Tests done show that although both algorithms present a high level of consistency, Fuzzy TOPSIS is more consistent than the proposed algorithm because, when adding a new alternative with a rating equal to one of the best ranked alternatives, M-40, rank reversal happened in the proposed algorithm, at just one time instant, but not in Fuzzy TOPSIS.

However, since rank reversal could be a logical effect in a traffic routing scenario when new roads are built, due to the changes it implies in the traffic state of the affected roads, it can be considered as a noncritical effect to select Fuzzy TOPSIS instead of the proposed algorithm for the decision making in the presented scenario. On the other hand, there were no changes in the importance order of the criteria when a new criterion was added in both algorithms.

Regarding computational complexity, it has been tested by computing the number of operations needed for both algorithms to obtain the ranking of alternatives. According to this factor, the proposed algorithm has proven to be more efficient than Fuzzy TOPSIS algorithm, since it needs a lower number of operations for ranking the alternatives.

\section{Competing Interests}

The authors declare no competing interests.

\section{Acknowledgments}

The European project Adaptive Cooperative Control in Urban (sub) Systems (ACCUS) (Project Code: ARTEMIS 333020) and the Spanish Ministerio de Industria, Energía y Turismo (Project Code: ART-010000-2013-2), have supported this work. J. Sendra was supported by the Spanish Ministerio de Economía y Competitividad and by the European Regional Development Fund (ERDF), under Project MTM2014-54141P.

\section{References}

[1] D. Washburn, U. Sindhu, S. Balaouras, R. Dines, N. Hayes, and L. Nelson, Helping Cios Understand 'Smart City' Initiatives: Defining the Smart City, Its Drivers, and the Role of the CIO, Forrester Research, Cambridge, Mass, USA, 2009.

[2] R. Kanter and S. Litow, "Informed and interconnected: a manifesto for smarter cities," Harvard Business School General Management Unit Working Paper 09-141, Harvard Business School, Boston, Mass, USA, 2009.

[3] S. Dirks and M. Keeling, A Vision of Smarter Cities: How Cities Can Lead the Way into a Prosperous and Sustainable Future, IBM Institute for Business Value, 2009.

[4] T. Watteyne and K. S. J. Pister, "Smarter cities through standards-based wireless sensor networks," IBM Journal of Research and Development, vol. 55, no. 1-2, 2011. 
[5] L. Figueiredo, I. Jesus, J. A. Tenreiro Machado, J. Rui Ferreira, and J. L. Martins De Carvalho, "Towards the development of intelligent transportation systems," in Proceedings of theIEEE Intelligent Transportation Systems Proceedings, vol. 88, pp. 12061211, August 2001.

[6] G. Dimitrakopoulos and P. Demestichas, "Intelligent transportation systems," IEEE Vehicular Technology Magazine, vol. 5, no. 1, pp. 77-84, 2010.

[7] S.-H. An, B.-H. Lee, and D.-R. Shin, "A survey of intelligent transportation systems," in Proceedings of the 3rd International Conference on Computational Intelligence, Communication Systems and Networks (CICSyN '11), pp. 332-337, IEEE, Bali, Indonesia, July 2011.

[8] S. C. Litescu, V. Viswanathan, A. Knoll, and H. Aydt, "The effect of information uncertainty in road transportation systems," Journal of Computational Science, vol. 16, pp. 170-176, 2016.

[9] C. Carlsson and R. Fullér, "Fuzzy multiple criteria decision making: recent developments," Fuzzy Sets and Systems, vol. 78, no. 2, pp. 139-153, 1996.

[10] R. E. Bellman and L. A. Zadeh, "Decision-making in a fuzzy environment," Management Science, vol. 17, no. 4, pp. B-141-B164, 1970.

[11] R. A. Ribeiro, "Fuzzy multiple attribute decision making: a review and new preference elicitation techniques," Fuzzy Sets and Systems, vol. 78, no. 2, pp. 155-181, 1996.

[12] J. Fülöp, "Introduction to decision making methods," in Proceedings of the BDEI-3 Workshop, Washington, DC, USA, 2005.

[13] E. Triantaphyllou and S. H. Mann, "An examination of the effectiveness of multi-dimensional decision-making methods: a decision-making paradox," Decision Support Systems, vol. 5, no. 3, pp. 303-312, 1989.

[14] W. Edwards and F. H. Barron, "SMARTS and SMARTER: improved simple methods for multiattribute utility measurement," Organizational Behavior and Human Decision Processes, vol. 60, no. 3, pp. 306-325, 1994.

[15] J. Mustajoki, R. P. Hämäläinen, and A. Salo, "Decision support by interval SMART/SWING-incorporating imprecision in the SMART and SWING methods," Decision Sciences, vol. 36, no. 2, pp. 317-339, 2005.

[16] R. L. Keeney and H. Raiffa, Decisions with Multiple Objectives: Preferences and Value Trade-Offs, Cambridge University Press, Cambridge, UK, 1993.

[17] E. Kornyshova, MADISE: method engineering-based approach for enhancing decision-making in information systems engineering [Ph.D. thesis], Université Panthéon-Sorbonne-Paris I, Paris, France, 2011.

[18] J. Figueira, V. Mousseau, and B. Roy, "Electre methods," in Multiple Criteria Decision Analysis: State of the Art Surveys, pp. 133-153, Springer, Berlin, Germany, 2005.

[19] J.-P. Brans and B. Mareschal, "Promethee methods," in Multiple Criteria Decision Analysis: State of the Art Surveys, J. Figueira, S. Greco, and M. Ehrogott, Eds., vol. 78 of International Series in Operations Research \& Management Science, chapter 5, pp. 163-186, Springer, Berlin, Germany, 2005.

[20] C. Kahraman, U. Cebeci, and D. Ruan, "Multi-attribute comparison of catering service companies using fuzzy AHP: the case of Turkey," International Journal of Production Economics, vol. 87, no. 2, pp. 171-184, 2004.

[21] S. Oguztimur, Why Fuzzy Analytic Hierarchy Process Approach for Transport Problems?, 2011.
[22] G. Kabir and M. Hasin, "Comparative analysis of topsis and fuzzy topsis for the evaluation of travel website service quality," International Journal for Quality Research, vol. 6, no. 3, pp. 657675, 2012.

[23] Y. S. Murat and N. Uludag, "Route choice modelling in urban transportation networks using fuzzy logic and logistic regression methods," Journal of Scientific and Industrial Research, vol. 67, no. 1, pp. 19-27, 2008.

[24] C.-L. Hwang and K. Yoon, Multiple Attribute Decision Making: Methods and Applications a Stateof-the-Art Survey, vol. 186, Springer Science \& Business Media, 2012.

[25] S.-J. Chen and C.-L. Hwang, Fuzzy Multiple Attribute Decision Making Methods, Springer, Berlin, Germany, 1992.

[26] K. P. Yoon and C.-L. Hwang, Multiple Attribute Decision Making: An Introduction, vol. 104, Sage, Thousand Oaks, Calif, USA, 1995.

[27] M. Behzadian, S. Khanmohammadi Otaghsara, M. Yazdani, and J. Ignatius, "A state-of the-art survey of TOPSIS applications," Expert Systems with Applications, vol. 39, no. 17, pp. 13051-13069, 2012.

[28] M. F. Aly, H. A. Attia, and A. M. Mohammed, "Integrated fuzzy (gmm)-topsis model for best design concept and material selection process," International Journal of Innovative Research in Science, Engineering and Technology, vol. 2, no. 11, pp. 64646486, 2013.

[29] Q. Xu, Y. B. Zhang, J. Zhang, and X. G. Lv, "Improved TOPSIS model and its application in the evaluation of NCAA basketball coaches," Modern Applied Science, vol. 9, no. 2, p. 259, 2015.

[30] T. L. Saaty, "How to handle dependence with the analytic hierarchy process," European Journal of Operational Research, vol. 48, no. 1, pp. 9-26, 1990.

[31] C. Li, S. G. Anavatti, and T. Ray, "Analytical hierarchy process using fuzzy inference technique for real-time route guidance system," IEEE Transactions on Intelligent Transportation Systems, vol. 15, no. 1, pp. 84-93, 2014.

[32] M. Berrittella, A. Certa, M. Enea, and P. Zito, "An analytic hierarchy process for the evaluation of transport policies to reduce climate change impacts," Social Science Research Network Electronic Paper Collection, 2007, http://ssrn.com/abstract= 962379.

[33] R. Banai, "Public transportation decision-making: a case analysis of the memphis light rail corridor and route selection with analytic hierarchy process," Journal of Public Transportation, vol. 9, no. 2, pp. 1-24, 2006.

[34] Y.-W. Chen, C.-H. Wang, and S.-J. Lin, "A multi-objective geographic information system for route selection of nuclear waste transport," Omega, vol. 36, no. 3, pp. 363-372, 2008.

[35] M. B. Ayhan, "A fuzzy AHP approach for supplier selection problem: a case study in a gear motor company," International Journal of Managing Value and Supply Chains, vol. 4, no. 3, pp. 11-23, 2013.

[36] V. González-Prida, P. Viveros, L. Barberá, and A. C. Márquez, "Dynamic analytic hierarchy process: AHP method adapted to a changing environment," Journal of Manufacturing Technology Management, vol. 25, no. 4, pp. 457-475, 2014.

[37] N. M. M. Noor, I. Sabri, M. Hitam, N. H. Ali, and F. Ismail, "Fuzzy analytic hierarchy process (FAHP) approach for evaluating tourism islands in Terengganu, Malaysia," in Proceedings of the International Conference on Communications and Information Technology, pp. 62-66, 2012. 
[38] Y.-M. Wang, "Centroid defuzzification and the maximizing set and minimizing set ranking based on alpha level sets," Computers and Industrial Engineering, vol. 57, no. 1, pp. 228236, 2009.

[39] Direccion General de Trafico Web Page, http://www.dgt.es/es/ la-dgt/quienes-somos/estructura-organica/centros-de-gestion/ sistemas-de-los-cgt/.

[40] Direccion general de trafico, http://infocar.dgt.es/etraffic/.

[41] F. R. L. Junior, L. Osiro, and L. C. R. Carpinetti, "A comparison between Fuzzy AHP and Fuzzy TOPSIS methods to supplier selection," Applied Soft Computing, vol. 21, pp. 194-209, 2014.

[42] V. Belton and T. Gear, "On a short-coming of Saaty's method of analytic hierarchies," Omega, vol. 11, no. 3, pp. 228-230, 1983.

[43] T. L. Saaty, "Making and validating complex decisions with the AHP/ANP," Journal of Systems Science and Systems Engineering, vol. 14, no. 1, pp. 1-36, 2005.

[44] S. Zahir, "Normalisation and rank reversals in the additive analytic hierarchy process: a new analysis," International Journal of Operational Research, vol. 4, no. 4, pp. 446-467, 2009. 


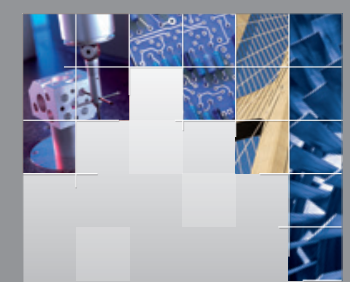

\section{Enfincering}
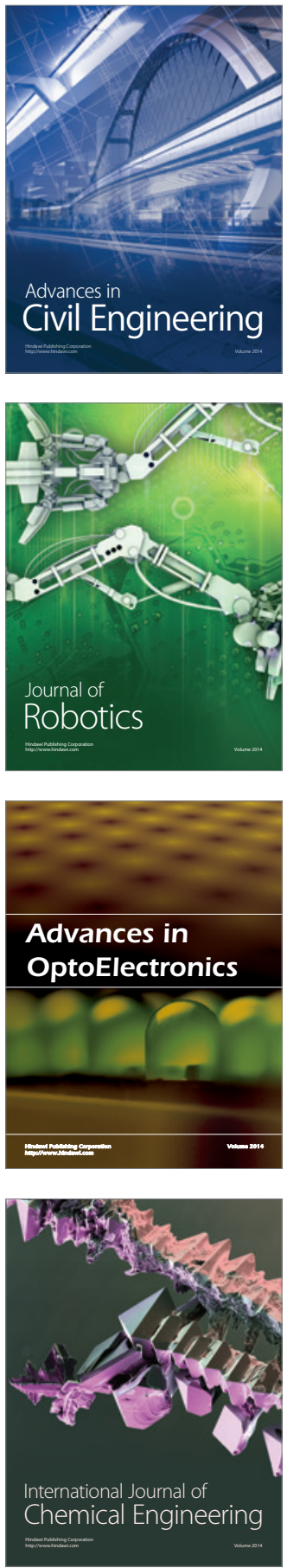

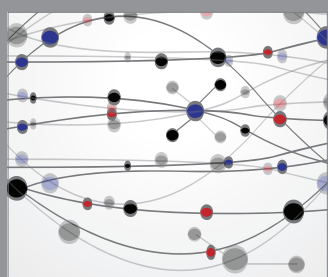

The Scientific World Journal

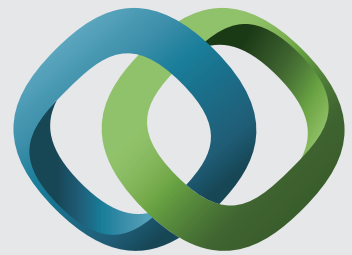

\section{Hindawi}

Submit your manuscripts at

http://www.hindawi.com
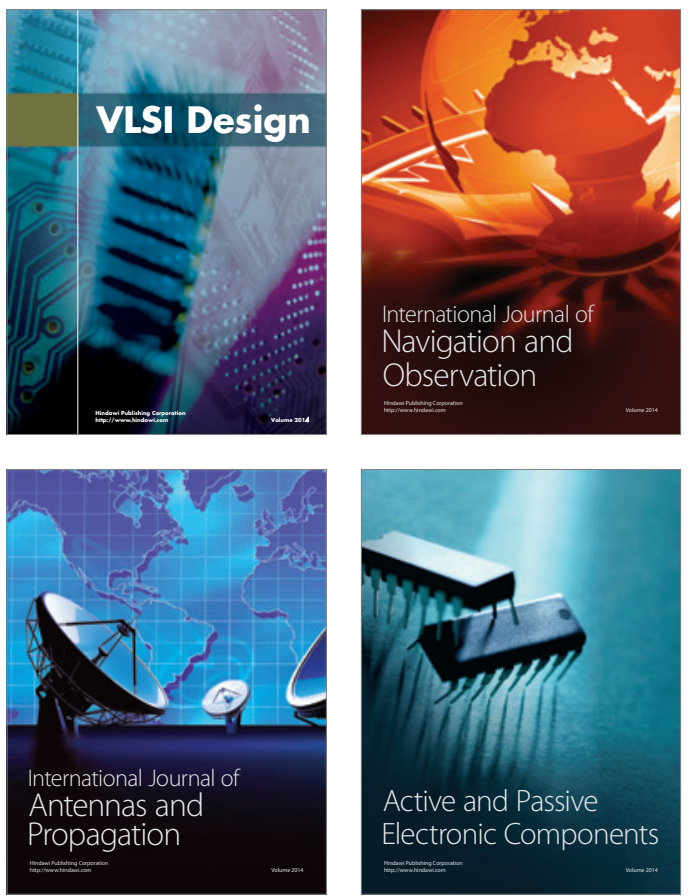
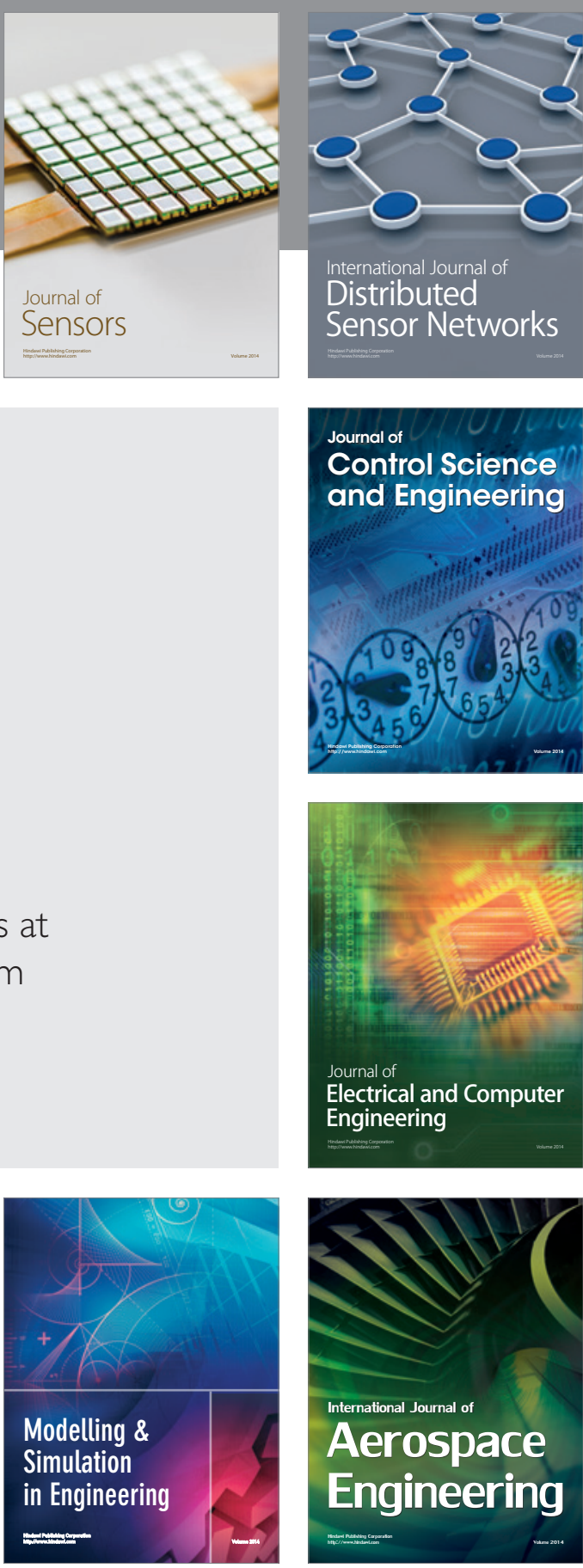

International Journal of

Distributed

Sensor Networks

Journal of

Control Science

and Engineering
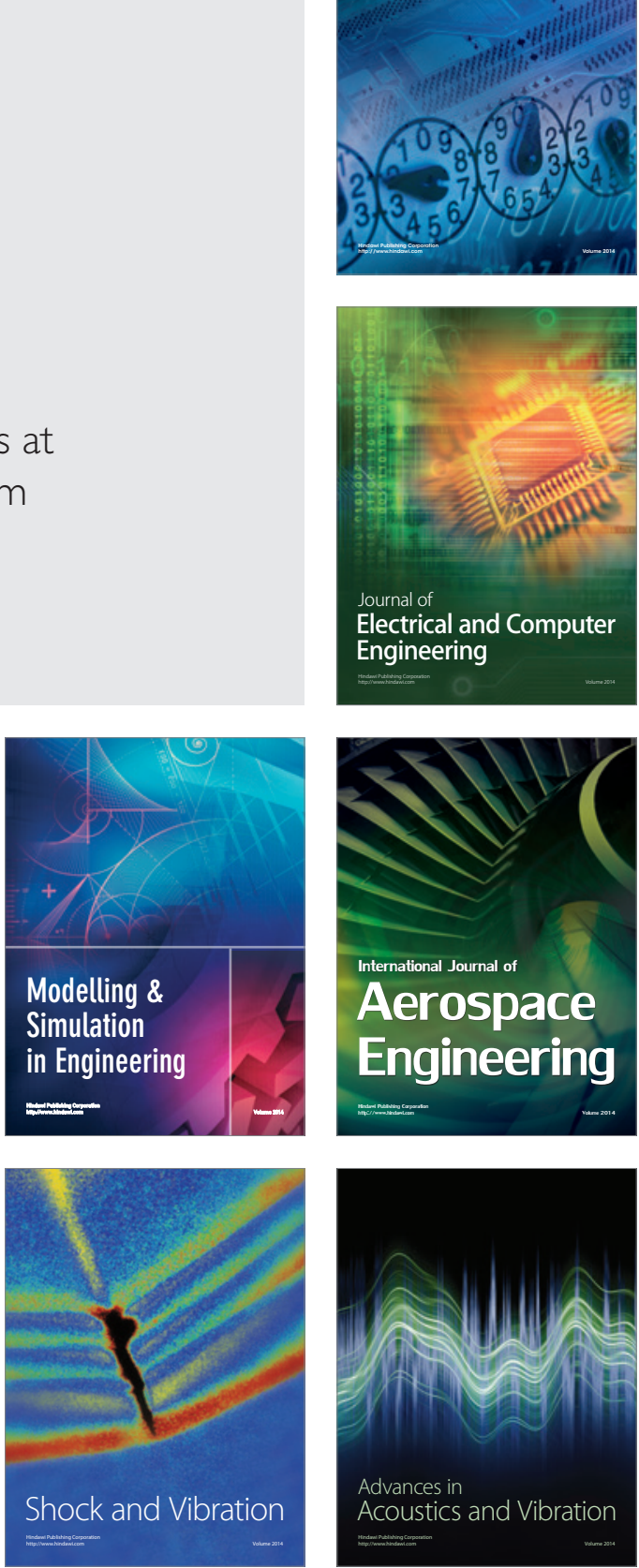